\title{
MODELAGEM DA DISPERSÃO DE POLUENTES DE ORIGEM MÓVEL (VEICULAR) EM CURITIBA E A OCORRÊNCIA DE BROMÉLIAS EM CABOS DA REDE ELÉTRICA
}

\author{
Juliano José da Silva Santos ${ }^{1}$, Tânia Lucia Graf de Miranda1, Rafael Geha Serta1, \\ Bernardo Lipski ${ }^{1}$ Katia Cristine da Costa Silva ${ }^{1}$ e Valéria Macedo ${ }^{1}$ \\ ${ }^{1}$ Institutos Lactec \\ E-mails: juliano.santos@lactec.org.br, tania.miranda@lactec.org.br, \\ rafael.serta@lactec.org.br, bernardo.lipski@lactec.org.br, katia.silva@lactec.org.br \\ e valeria.macedo@lactec.org.br
}

\section{RESUMO}

A ocorrência das bromélias atmosféricas (Tillandsia $s p$ ) nas redes de distribuição de energia proporciona um efeito visual negativo e custos de limpeza para as empresas. Apesar dos estudos existentes, as informações não explicam quais as condições propícias para o fenômeno. Para se obter dados sobre a qualidade do ar em Curitiba, tendo em vista que as bibliografias apontam este gênero como uma planta bioindicadora, foi realizada uma modelagem da dispersão de poluentes atmosféricos através do programa AERMOD, utilizado pela United States Environmental Protection Agency. Foram simuladas as concentrações dos poluentes: material particulado, óxido de nitrogênio, hidrocarbonetos totais, monóxido de carbono e dióxido de enxofre. Foram levantados 26 pontos dentro do perímetro urbano com a presença das bromélias nos cabos. Nestes pontos foram observadas as fontes emissoras atmosféricas, presença de vegetação e tipo de área do zoneamento municipal. Através da modelagem foi possível determinar os valores médios e máximos das concentrações dos poluentes medidos, entre 2007 a 2011 . O tratamento estatístico utilizando a Análise de Componentes Principais indicou uma correlação entre fontes antrópicas, em sua maioria móveis e de emissões veiculares que combinadas a fatores atmosféricos propiciam condições para a presença das bromélias nos cabos.

\section{INTRODUÇÃO}

A Agência Nacional de Energia Elétrica (ANEEL) é a instituição que regula as questões relativas à geração e distribuição de energia no Brasil. A ANEEL realiza inspeções nas redes de distribuição em todo o país muitas vezes encontrando grandes quantidades de bromélias estabelecidas sobre os cabos dentro do perímetro urbano das cidades e em áreas rurais. A limpeza dos cabos é feita manualmente pelas concessionárias com elevados custos e sendo que novas infestações sempre são recorrentes. A solução deste tipo de problema passa pelo estudo das condições fisiológicas e de crescimento da planta e pela análise detalhada do ambiente do entorno destas ocorrências bem como da proposição de soluções preventivas que evitem a novas infestações. 
A presença das bromélias do gênero Tillandsia spp nas redes de distribuição de energia elétrica causam um efeito visual negativo passando a impressão de abandono ou falta de manutenção. A infestação pode causar impactos, desde paisagísticos até de segurança do sistema elétrico. Por exemplo, o acúmulo das bromélias dificulta a inspeção visual dos cabos, impedindo a verificação preventiva de defeitos pelas equipes de manutenção. Além disto, uma grande quantidade destas plantas ocasiona peso adicional, descalibrando o tensionamento e aproximando os condutores. Este fenômeno tem sido relatado em literatura com a ocorrência em vários centros urbanos no mundo. São conhecidos casos em países como Panamá [1], Argentina [2] e México [3]. No Brasil, o fenômeno já foi observado em cidades como Pelotas, Porto Alegre, São Paulo, Curitiba e na cidade de Ponta Grossa, onde a infestação ocupa vários trechos de cabos contínuos. Em Curitiba, objeto do estudo de caso em questão, elas são encontradas em cabos de rede aéreos e a maioria são bromélias atmosféricas do gênero (Tillandsia spp. Bromeliaceae) como pode ser observado na Figura 1.

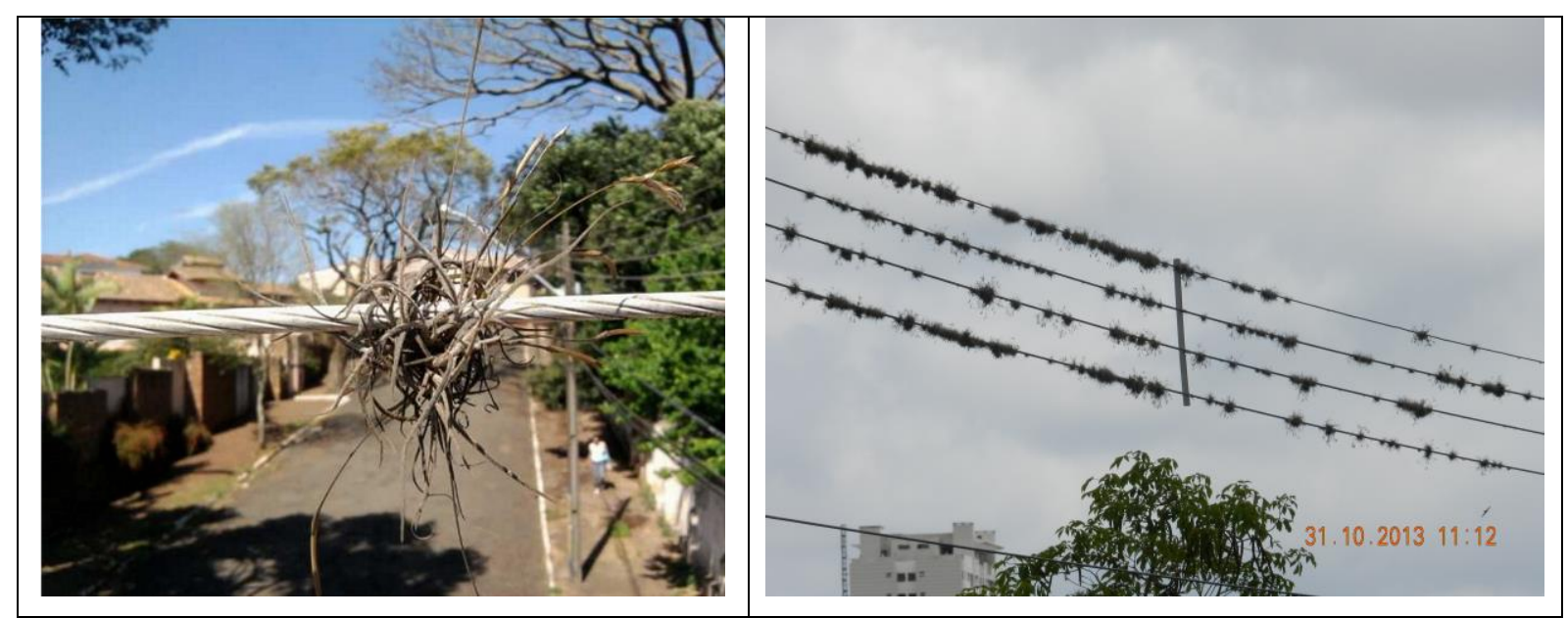

Figura 1 - Bromélias (Tillandsia recurvata) nos cabos das redes de energia em Curitiba.

Fonte: Os autores (2014).

\subsection{OBJETIVOS}

Identificar e analisar a presença das bromélias epífitas nas redes de energia e sua relação com as condições ambientais atmosféricas e modelar matematicamente as condições meteorológicas e as fontes de emissão nas áreas de ocorrência destas plantas.

\subsection{ESTUDOS JÁ REALIZADOS}

A relação das espécies do gênero Tillandsia com as redes de distribuição de energia é de longo tempo conhecida e de ampla ocorrência geográfica, embora pouco estudada. Reitz [3] relata infestações que remontam a 1951 no estado de Santa Catarina, enquanto Puente \& Bashan [4], Abril \& Bucher [2] , Wester \& Zotz [1] e Barrat [5] detalham o estabelecimento e crescimento de espécies do gênero, respectivamente, no México, Argentina, Costa Rica e Panamá. Kremer cita que as espécies Tillandsia stricta e Tillandsia recurvata possuem grande ocorrência nas áreas urbanas do Brasil [6]. 
Os autores esclarecem que a cobertura de escamas, é uma adaptação fundamental ao ambiente epifítico, tornando as bromélias sensíveis às mudanças e perturbações das condições ambientais, podendo ser os primeiros indicadores bióticos das mudanças climáticas globais.[7] , [8], [9].

A pesquisa desenvolvida por Abril \& Bucher [2] comparou a fonte de nutrientes para a epífita Tillandsia capillaries localizadas em árvores e em cabos de energia na cidade de Córdoba, Argentina. Os resultados indicam que T. capillaris tem fontes de nutrientes semelhantes em ambos os suportes, e, consequentemente, as bromélias epífitas não dependem de uma planta ou local de fixação para obter nutrientes.

A publicação de Wester \& Zotz [1] apresentou o resultado relativo ao crescimento e sobrevivência da Tillandsia flexuosa em cabos da rede elétrica no Panamá. As medições ao longo de dois anos indicaram que a taxa de mortalidade dos dois grupos foi similar, mas o número de indivíduos novos nos cabos foi muito abaixo daquele localizados nas árvores. Isto implica em um crescimento populacional das bromélias localizadas nos cabos, mais lento e com processo de colonização menos eficiente se comparada àquelas localizadas nas árvores. Segundo os autores esta situação ocorre graças à menor disponibilidade de água nas plantas dos cabos.

Estudos abordam o uso de várias espécies de bromélias como bioindicadores da poluição atmosférica, principalmente por metais pesados. Por exemplo, o estudo para quantificação de metais pesados acumulados em Tillandsia capillaris para identificar as principais fontes de emissão dos metais na região de Córdoba, Argentina [10] e [11]

Ainda pode-se citar os estudos com Tillandsia usneoides para determinação da poluição atmosférica na área industrial da cidade do México [12] e o uso de Tillandsia capillaris como bioindicadora na cidade de Stuttgart, Alemanha [11] e a avaliação da acumulação de metais pesados em duas espécies de Tillandsia em relação as emissões atmosféricas na província de Córdoba na Argentina [10]

Em Curitiba, a espécie Tillandsia stricta foi utilizada para avaliar a poluição atmosférica com ênfase na emissão veicular de compostos orgânicos voláteis e sua relação com a densidade da vegetação em alguns pontos da cidade. Os resultados mostraram índices alarmantes destes compostos com potencial carcinogênico nos locais amostrados e também alterações na estrutura das plantas utilizadas [13].

É importante salientar que quase a totalidade destes estudos avaliou as questões atmosféricas através da aquisição de dados da presença de poluentes retirando compostos químicos diretamente da biomassa das plantas, principalmente das folhas e raízes das bromélias. A proposta deste estudo, no entanto, é relacionar a ocorrência das bromélias nas redes elétricas, com a concentração de poluentes nos locais de ocorrência (concentração média), através da modelagem matemática (AERMOD) e não coletando indivíduos para análise em laboratório. 


\section{METODOLOGIA}

Os cinco poluentes modelados neste estudo foram o Monóxido de Carbono (CO), Óxidos de Nitrogênio $\left(\mathrm{NO}_{x}\right)$, Dióxido de enxofre $\left(\mathrm{SO}_{2}\right)$, Material Particulado (MPT) e Hidrocarbonetos (THC). Iremos detalhar algumas informações a respeito destes gases a seguir.

\subsection{LOCAL DE ESTUDO}

A área do estudo é o município de Curitiba. Para o levantamento dos pontos de ocorrência de bromélias nos cabos elétricos no município de Curitiba até o período de elaboração do estudo (Janeiro de 2014), foram obtidas informações de pontos através dos técnicos de manutenção das redes de distribuição da COPEL (Polo Km 3) que apresentam periodicamente relatórios de atividades onde citam este tipo de situação. Após a obtenção das informações, foram indicados 26 pontos com a presença de bromélias na rede e através de três fases de campo (31/10/2013, 24/12/2013 e 25/12/2013) foram analisados em cada local características com relação a ocupação da região, se a área é industrial (qual tipo de indústria) ou residencial, central ou periférica, proximidade com corpos hídricos e se há presença de fragmentos e remanescentes florestais próximos a rede, além de árvores isoladas nos quintais de residências e na arborização urbana (parques, praças e arborização de ruas). Também foi anotado em que tipo de estrutura/local as bromélias ocorrem, se somente nos cabos das redes de energia ou também em postes, jumpers, além de outras estruturas urbanas, como cabos de telefonia, antenas e construções.

\subsection{MODELAGEM MATEMATICA NO AERMOD}

Para avaliação das condições meteorológicas de dispersão de poluentes na região de estudo foi utilizado o modelo matemático de dispersão de poluentes AERMOD. Este é um modelo de pluma gaussiana estacionário, desenvolvido pela AERMIC (American Meteorological Society/EPA Regulatory Model Improvement Committee) e pela United States Environmental Protection Agency (EPA) para calcular a concentração de poluentes em um ponto no entorno da fonte de emissão (EPA, 2004). Para simular a dispersão de poluentes na atmosfera, o modelo utiliza dados de fonte emissora, dados meteorológicos de superfície e de altitude, dados de topografia, dados dos receptores e uso do solo.

O AERMOD é um software recomendado pela USEPA e amplamente utilizado para, por exemplo, prever impactos de novos empreendimentos; indicar locais para a instalação de estações de monitoramento de qualidade do ar; verificar o atendimento à legislação vigente por parte das indústrias/empresas; estudo de áreas com elevada concentração de poluentes para avaliação da degradação de materiais, entre outras finalidades [14].

O modelo matemático foi calibrado com os dados de medição obtidos nas estações de qualidade do ar localizadas na Cidade de Curitiba.

Foram consideradas no modelo as fontes industriais (fontes fixas) e fontes veiculares (fontes móveis). O procedimento para considerar a emissão veicular no modelo AERMOD é através da inserção de segmentos (linhas) que representam as 
vias de tráfego. Cada segmento possui um comprimento e uma taxa de emissão, portanto, é necessário definir as vias a serem modeladas e conhecer a taxa de emissão veicular da frota total de Curitiba para posteriores adaptações dessas taxas aos cenários modelados.

Tabela 1 - Número de fontes de emissão dos poluentes.

\begin{tabular}{|c|c|c|c|c|c|}
\hline \multirow[b]{2}{*}{ Poluente } & \multicolumn{2}{|c|}{ Fontes veiculares } & \multicolumn{3}{|c|}{ Fontes industriais } \\
\hline & Quantidade & $\begin{array}{c}\text { Taxa } \\
\text { (g/s) }\end{array}$ & $\begin{array}{c}\text { Quantidade } \\
\text { Ind. }\end{array}$ & $\begin{array}{c}\text { Quantidade } \\
\text { Fontes }\end{array}$ & $\begin{array}{l}\text { Taxa } \\
(\mathrm{g} / \mathrm{s})\end{array}$ \\
\hline MPT & \multirow{5}{*}{116 vias } & 3,64 & 18 & 35 & 22,65 \\
\hline THC & & 169,6 & 13 & 56 & 21,4 \\
\hline $\mathrm{NOx}$ & & 39,4 & 20 & 55 & 45,69 \\
\hline $\mathrm{SO}_{2}$ & & 9,28 & 10 & 19 & 12,3 \\
\hline $\mathrm{CO}$ & & 672,3 & 65 & 112 & 146,49 \\
\hline
\end{tabular}

Fonte: LACTEC, 2011.

Foi utilizada a Análise de Componentes Principais (ACP) para agrupar e analisar as bromélias em relação aos poluentes modelados (MPT, THC, $\mathrm{NO}$, $\mathrm{SO}_{2}$ e CO). $\mathrm{O}$ primeiro passo do trabalho, portanto, consistiu em adaptar os dados obtidos em campo e através da modelagem. Para cada um dos 26 pontos, com a presença de bromélias, foram obtidas as concentrações dos poluentes modelados e dividido em 6 intervalos de classes para cada poluente conforme a concentração máxima e mínima obtida de todos os pontos de interesse. Para cada ponto foi analisado em qual intervalo de classe estava a concentração do poluente. Além disso, foi dividido em 3 intervalos de classe em relação ao número de bromélias nos fios elétricos (baixa, média e alta) mediante diagnóstico visual.

A Análise dos Componentes Principais ou PCA (Principal Component Analysis) é um método que tem por finalidade básica, a análise dos dados usados visando sua redução, eliminação de sobreposições e a escolha das formas mais representativas de dados a partir de combinações lineares das variáveis originais [15].

Esta metodologia foi escolhida por se tratar de um método exploratório que auxilia na elaboração de hipóteses gerais a partir dos dados coletados, contrastando com estudos direcionados nos quais hipóteses prévias são testadas. $E$ também é capaz de separar a informação relevante dos dados obtidos, apresentar a visualização de diversas variáveis em um determinado conjunto de dados, tornando-a mais objetiva na determinação de correlações.

\section{RESULTADOS}

O AERMOD permite a inclusão de pontos de interesse (receptores discretos), além da grade de receptores. Neste estudo os receptores discretos são as coordenadas dos locais de ocorrência de bromélias nos cabos da rede. Para todos eles, foram avaliadas a concentração média (período) e a máxima (horária) de poluentes atmosféricos para os anos modelados. 
A Tabela 2 apresenta os valores resultantes da aplicação do modelo matemático nos 26 pontos de ocorrência de bromélias e as respectivas concentrações de poluentes em termos de valores médios.

Tabela 2 - Resultados obtidos pela modelagem nos pontos de ocorrência das bromélias (receptores discretos) em $\mu \mathrm{g} / \mathrm{m}^{3}$.

\begin{tabular}{|l|c|c|c|c|c}
\hline \multirow{2}{*}{ LCAL } & SO2 & NOx & THC & MPT & CO \\
\cline { 2 - 6 } & MEDIA & MEDIA & MEDIA & MEDIA & MEDIA \\
\hline P1 & 4,44 & 18,18 & 65,86 & 2,68 & 268,56 \\
\hline P2 & 12,46 & 55,75 & 212,61 & 8,16 & 857,14 \\
\hline P3 & 15,94 & 67,18 & 291,55 & 8,43 & 1104,75 \\
\hline P4 & 4,70 & 19,86 & 71,38 & 2,92 & 286,71 \\
\hline P5 & 7,17 & 32,64 & 119,35 & 5,16 & 485,14 \\
\hline P6 & 14,32 & 60,25 & 238,16 & 8,05 & 959,54 \\
\hline P7 & 18,41 & 77,05 & 322,17 & 8,51 & 1261,02 \\
\hline P8 & 7,12 & 30,52 & 87,06 & 6,68 & 392,53 \\
\hline P9 & 13,24 & 57,97 & 227,10 & 8,16 & 904,42 \\
\hline P10 & 5,04 & 30,55 & 75,44 & 4,97 & 322,95 \\
\hline P11 & 13,52 & 56,00 & 218,61 & 7,58 & 886,67 \\
\hline P12 & 12,70 & 57,34 & 214,17 & 8,53 & 876,43 \\
\hline P13 & 15,67 & 66,12 & 271,50 & 8,04 & 1068,49 \\
\hline P14 & 19,29 & 81,27 & 340,45 & 8,97 & 1334,34 \\
\hline P15 & 16,38 & 68,76 & 286,69 & 7,71 & 1122,72 \\
\hline P16 & 26,99 & 111,69 & 464,39 & 12,55 & 1819,75 \\
\hline P17 & 18,40 & 78,05 & 317,81 & 9,69 & 1266,39 \\
\hline P18 & 10,02 & 40,50 & 151,07 & 5,56 & 608,85 \\
\hline P19 & 6,59 & 27,19 & 107,25 & 3,83 & 427,06 \\
\hline P20 & 5,41 & 23,01 & 86,35 & 3,64 & 346,41 \\
\hline P21 & 6,48 & 26,73 & 101,58 & 3,47 & 413,04 \\
\hline P22 & 15,21 & 66,35 & 253,61 & 8,98 & 1109,83 \\
\hline P23 & 15,08 & 63,81 & 263,86 & 7,50 & 1039,04 \\
\hline P24 & 18,12 & 76,18 & 318,57 & 8,42 & 1247,39 \\
\hline P25 & 23,37 & 92,13 & 382,05 & 10,13 & 1493,32 \\
\hline P26 & 28,74 & 116,38 & 487,63 & 12,66 & 1900,86 \\
\hline
\end{tabular}

Fonte: Os autores (2014)

Observa-se que as maiores médias para os poluentes $\mathrm{SO}_{2}, \mathrm{NOx}$, THC, MPT e CO foram obtidas nos pontos P16 e P26 sendo o primeiro localizado no bairro esse onde existe intenso tráfego de veículos e o segundo em área com intensa concentração de quintais com árvores. 


\subsection{Material particulado total (MPT)}

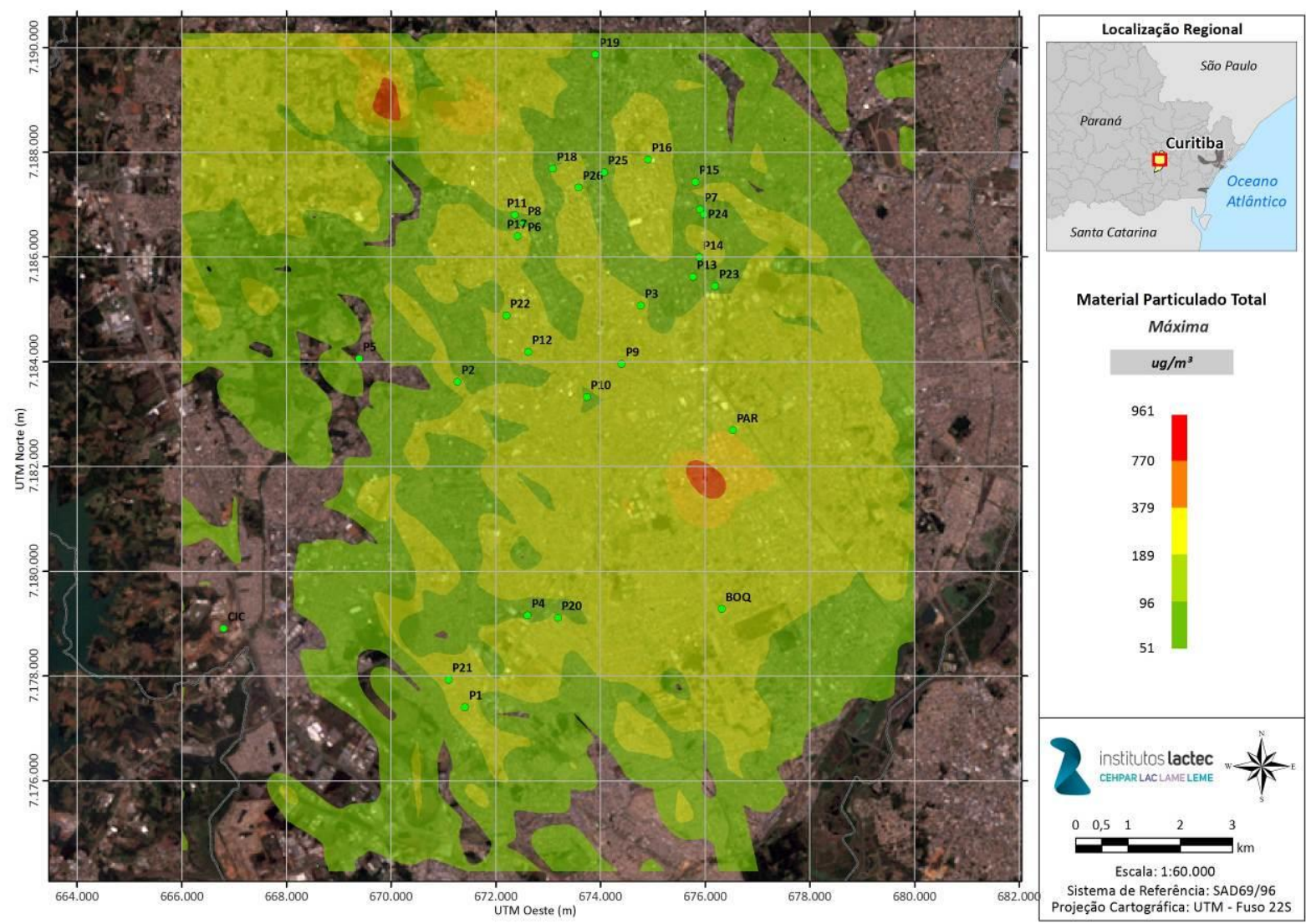

Figura 2 - Pluma da concentração máxima de Material Particulado obtida na modelagem Fonte: Os autores (2014)

A Figura 3 apresenta os dados da concentração de material particulado (MPT) em cada ponto do estudo.

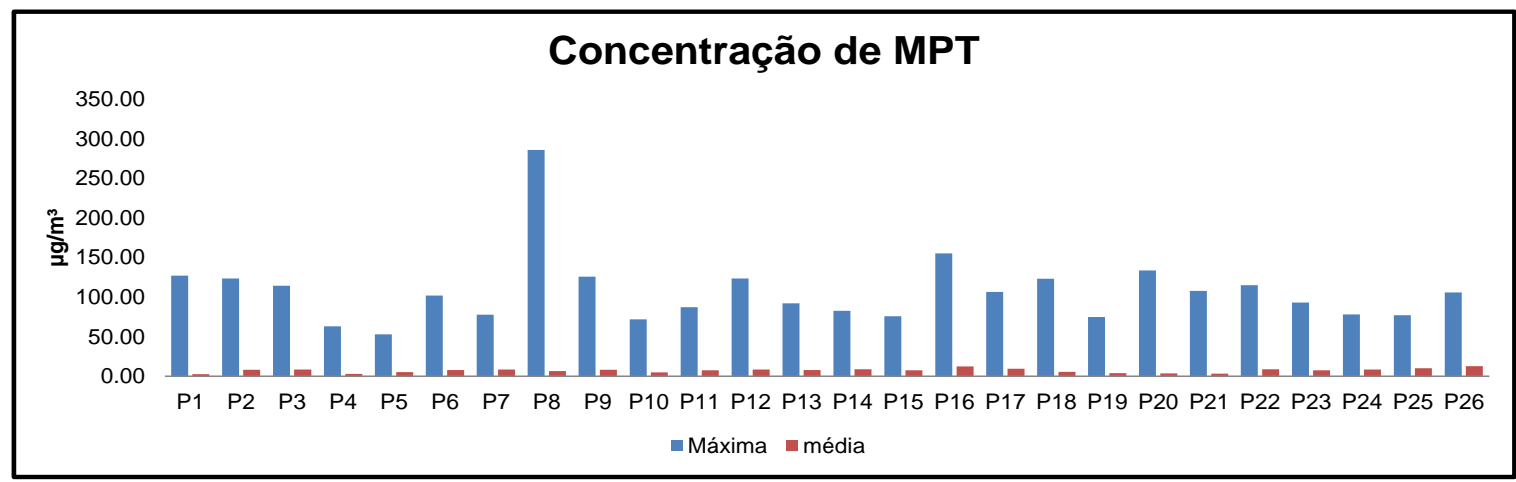

Figura 3 - Concentração de material particulado

Fonte: Os autores (2014)

A maior concentração de MPT foi observado no ponto 8, o mais central da Figura 2, com $285,98 \mu \mathrm{g} / \mathrm{m} 3$. É um local com significativa concentração de bromélias nos cabos em um trecho da rede, além da presença de arborização. Metade dos pontos (P1, P2, P3, P6, P9, P12, P16, P17, P18, P20, P21, P22 e P26), foram observadas concentrações acima de $100 \mu \mathrm{g} / \mathrm{m} 3$. Nos pontos restantes, as concentrações ficaram entre 53,06 $\mu \mathrm{g} / \mathrm{m} 3$ (Ponto 5) e 93,08 $\mu \mathrm{g} / \mathrm{m3}$. 
As concentrações médias maiores ficaram na região mais central da cidade onde 0 transito de veículos é intenso. Elas variaram entre 2,62 $\mu \mathrm{g} / \mathrm{m} 3$ e 12,66 $\mu \mathrm{g} / \mathrm{m} 3$.

\subsection{Monóxido de carbono (CO)}

A Figura 4 apresenta os dados da concentração de CO.

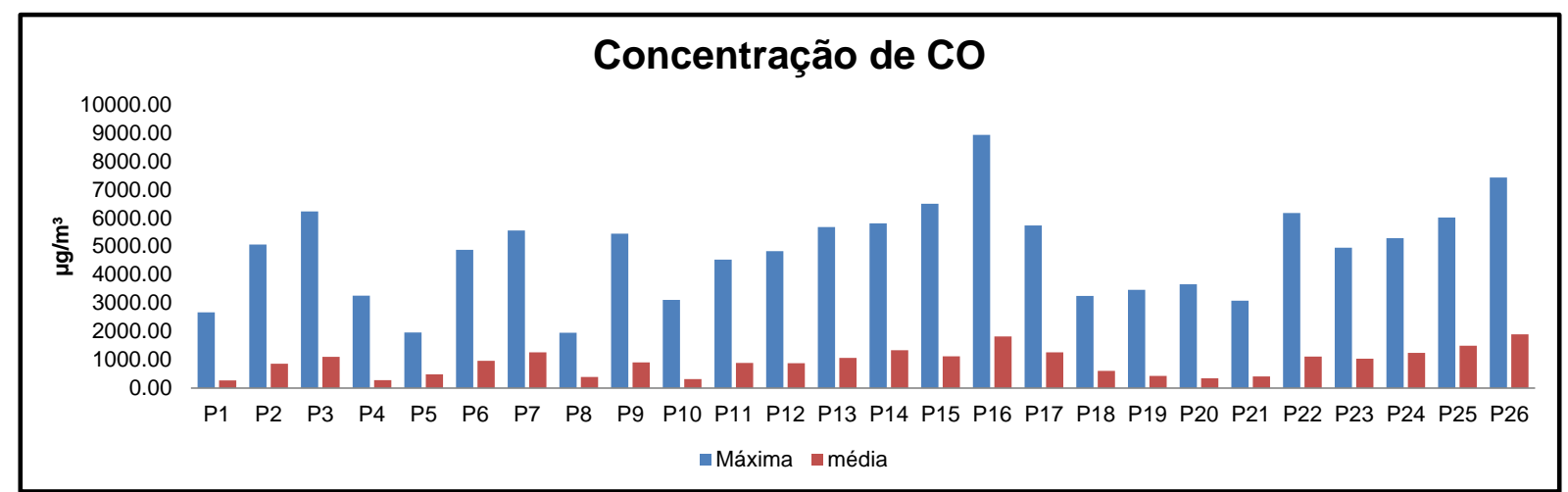

Figura 4 - Concentração de CO

Fonte: Os autores (2014).

O CO é um poluente atmosférico de origem de fontes móveis em sua maioria. Como o trafego de veículos é intenso no centro de Curitiba é presumível que as maiores concentrações deste poluente fossem encontradas nesta região. A modelagem confirmou esta hipótese, pois nos pontos mais próximos ao anel central como P16 $(8926,40 \mu \mathrm{g} / \mathrm{m} 3)$ e P3, P15, P22, P25 e P26 as concentrações ficaram acima de $6000 \mu \mathrm{g} / \mathrm{m} 3$. Nos outros pontos os valores máximos ficaram com concentrações entre $1950,61 \mu \mathrm{g} / \mathrm{m} 3$ e $5811 \mu \mathrm{g} / \mathrm{m} 3$.

A Figura 5 apresenta a Pluma da concentração média de CO obtida na modelagem. 


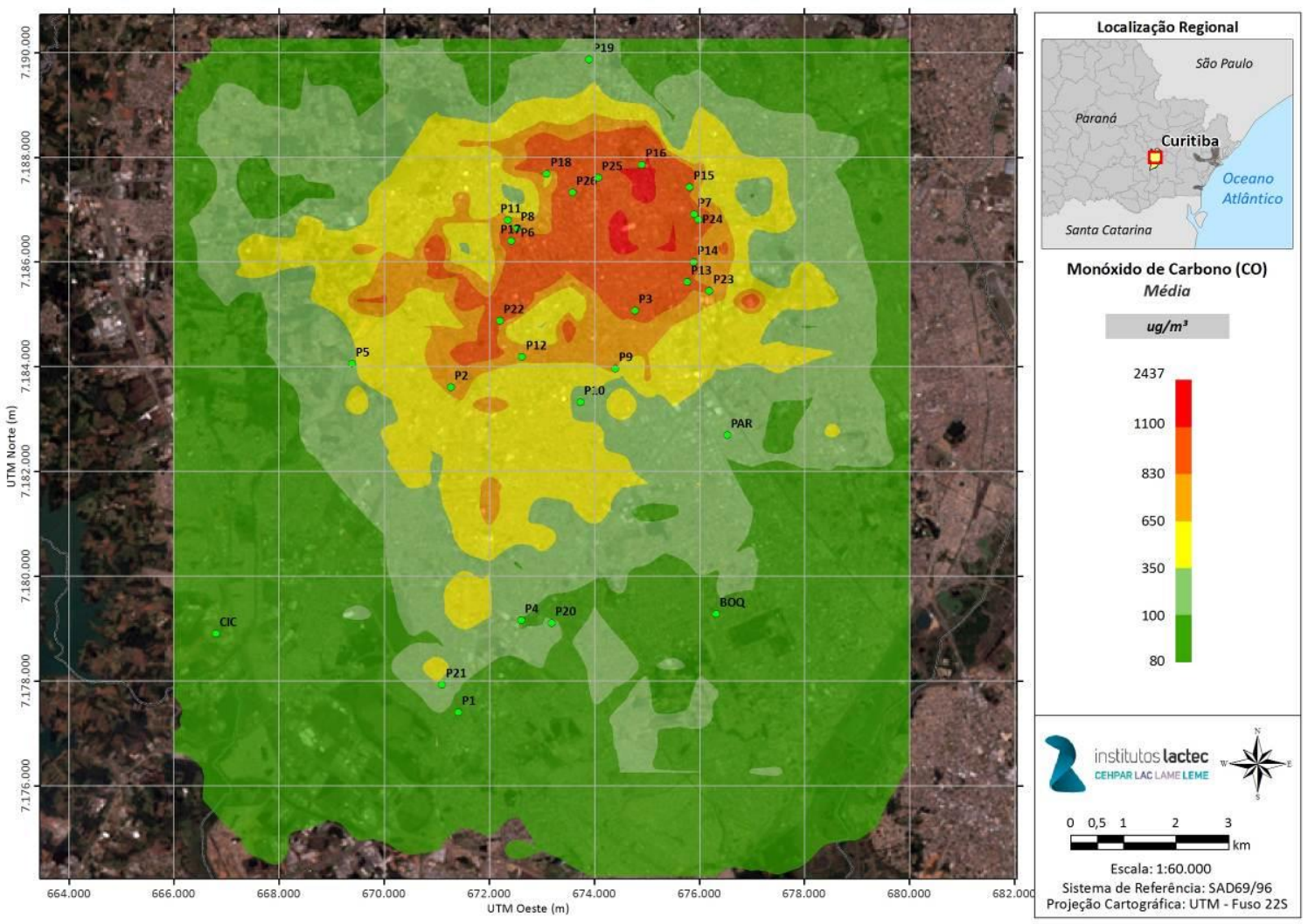

Figura 5 - Pluma da concentração média de CO obtida na modelagem Fonte: Os autores (2014).

\section{3 Óxidos de nitrogênio (NOx)}

A Figura 6 apresenta a concentração de NOx obtida através da modelagem matemática.

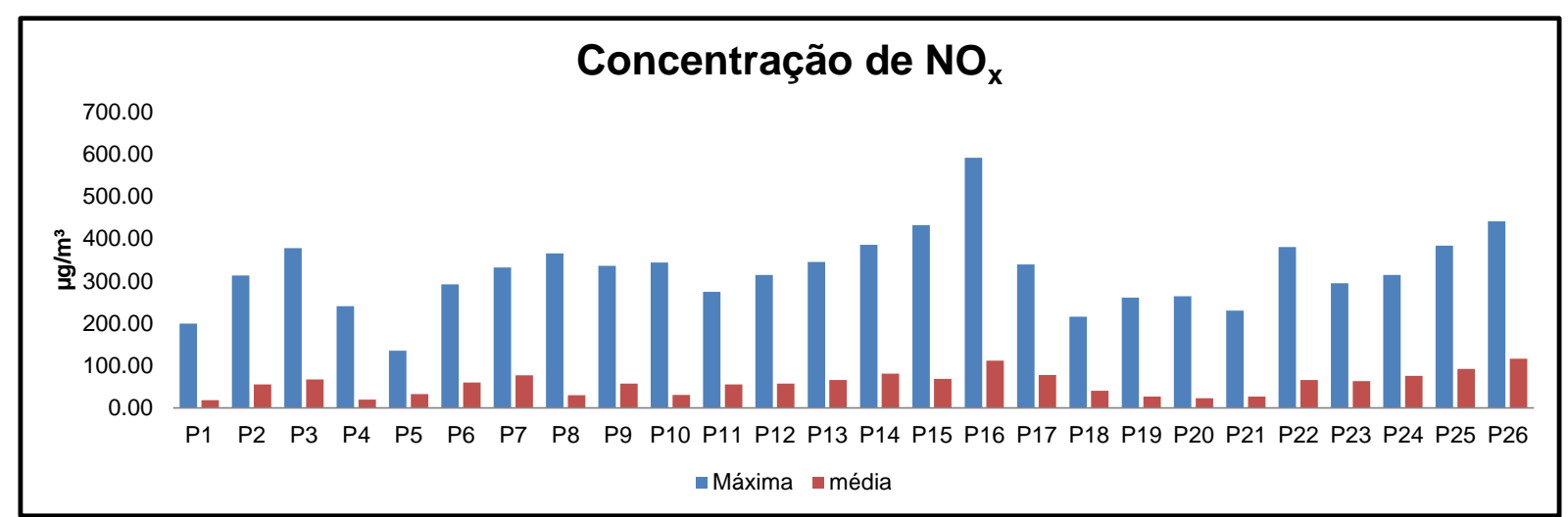

Figura 6 - Concentração de NOx

Fonte: Os autores (2014).

Com relação as concentrações máximas de NOx, sete pontos tiveram concentração acima dos $350 \mu \mathrm{g} / \mathrm{m} 3$ (P3, P8, P14, P15, P22, P25 e P26). A menor concentração foi

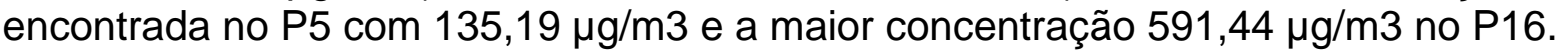




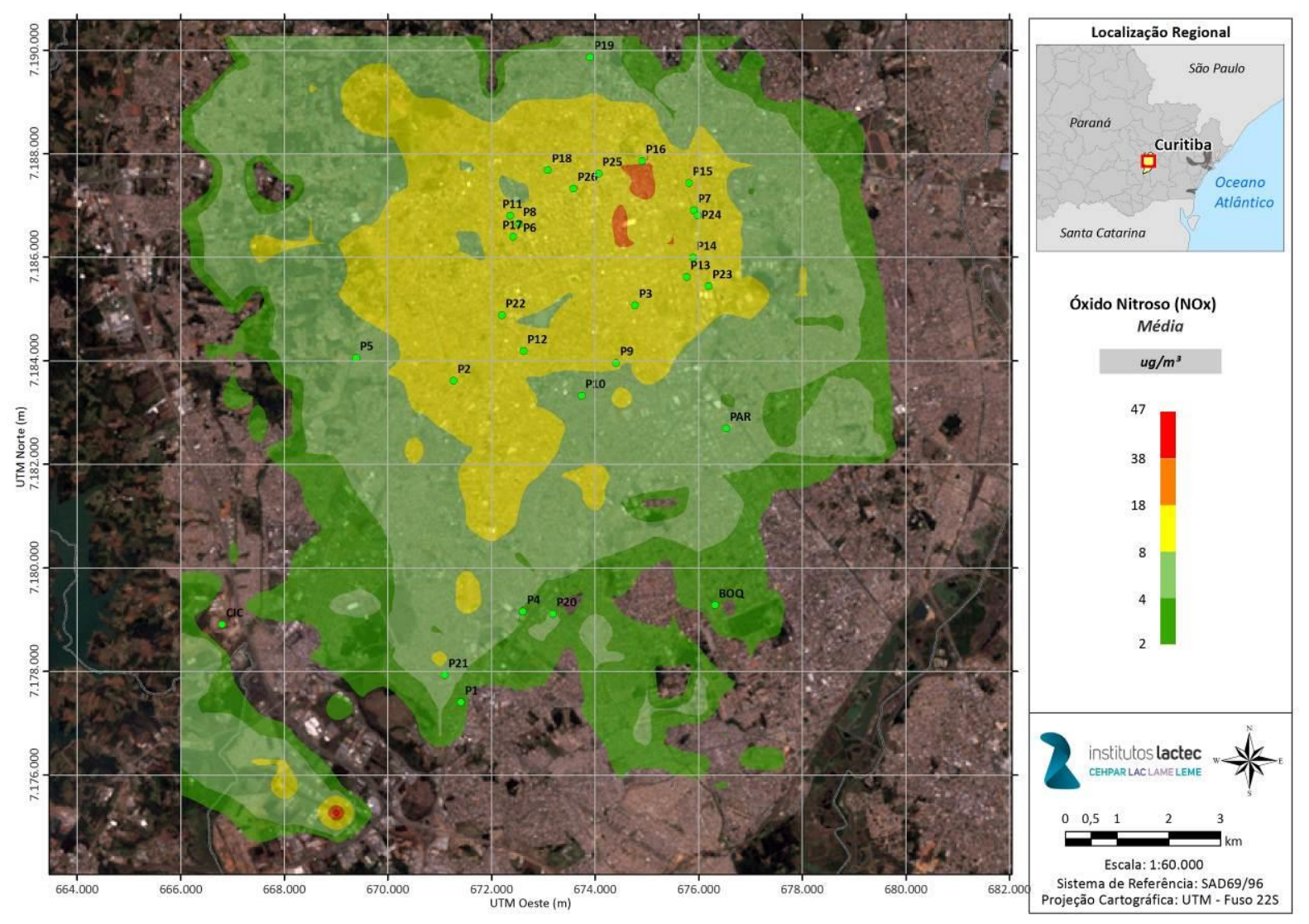

Figura 7 - Pluma da concentração média de NOx obtida na modelagem Fonte: Os autores (2014).

As medias das concentrações de NOx foram maiores quanto mais próximas ao centro, sendo esta uma tendência relacionada a emissão de fontes móveis (veiculares). O P26 obteve a maior média $(116,38 \mu \mathrm{g} / \mathrm{m} 3)$ e os pontos P7, P14, P16, P17, P24 e P25 ficaram com concentrações entre 76,18 $\mu \mathrm{g} / \mathrm{m} 3$ e 111,69 $\mu \mathrm{g} / \mathrm{m} 3$.

\subsection{Dióxido de enxofre $\left(\mathrm{SO}_{2}\right)$}

A Figura 8 apresenta os dados da concentração de SO2 em cada ponto selecionado.

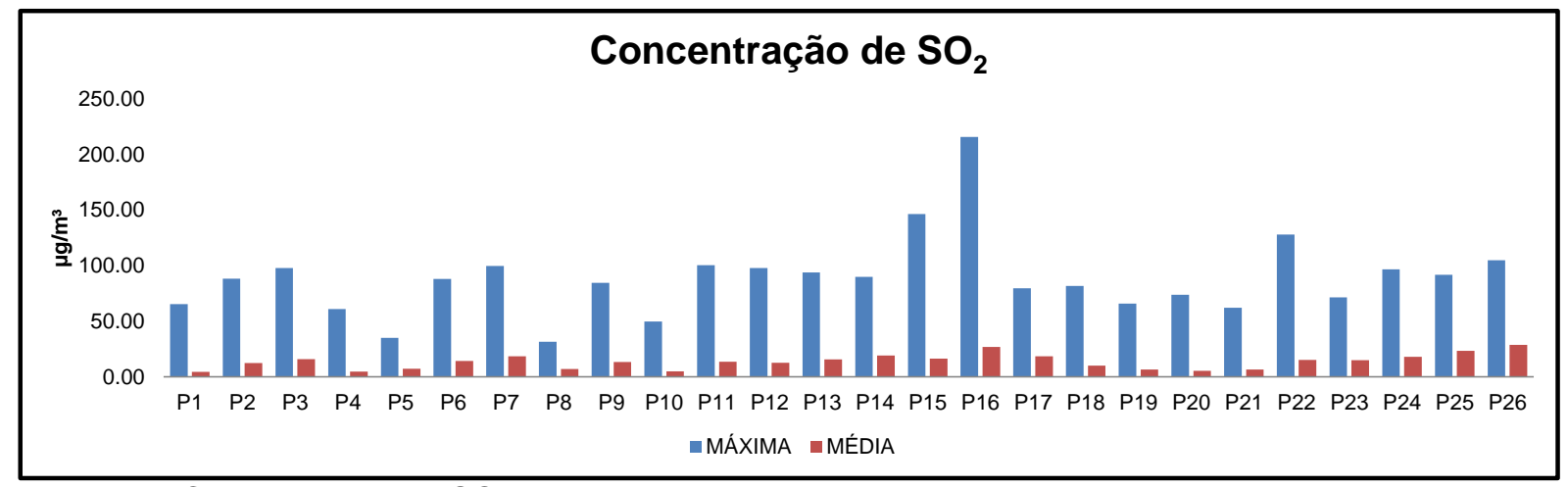

Figura 8 - Concentração de $\mathrm{SO}_{2}$

Fonte: Os autores (2014). 
As concentrações máximas de dióxido de enxofre se distribuíram além da região central para o sul de Curitiba também, pois se trata de uma área com concentração de indústrias (fontes fixas). Os maiores valores observados foram no P16 com $215,73 \mu \mathrm{g} / \mathrm{m} 3$, e os pontos P3, P7, P11, P12, P13, P14, P22, P24, P25 e P26, todos com concentrações acima de $90,01 \mu \mathrm{g} / \mathrm{m} 3$, e localizados na região central.

A Figura 9 apresenta a pluma das concentrações de $\mathrm{SO}_{2}$ obtidos a partir da modelagem matemática

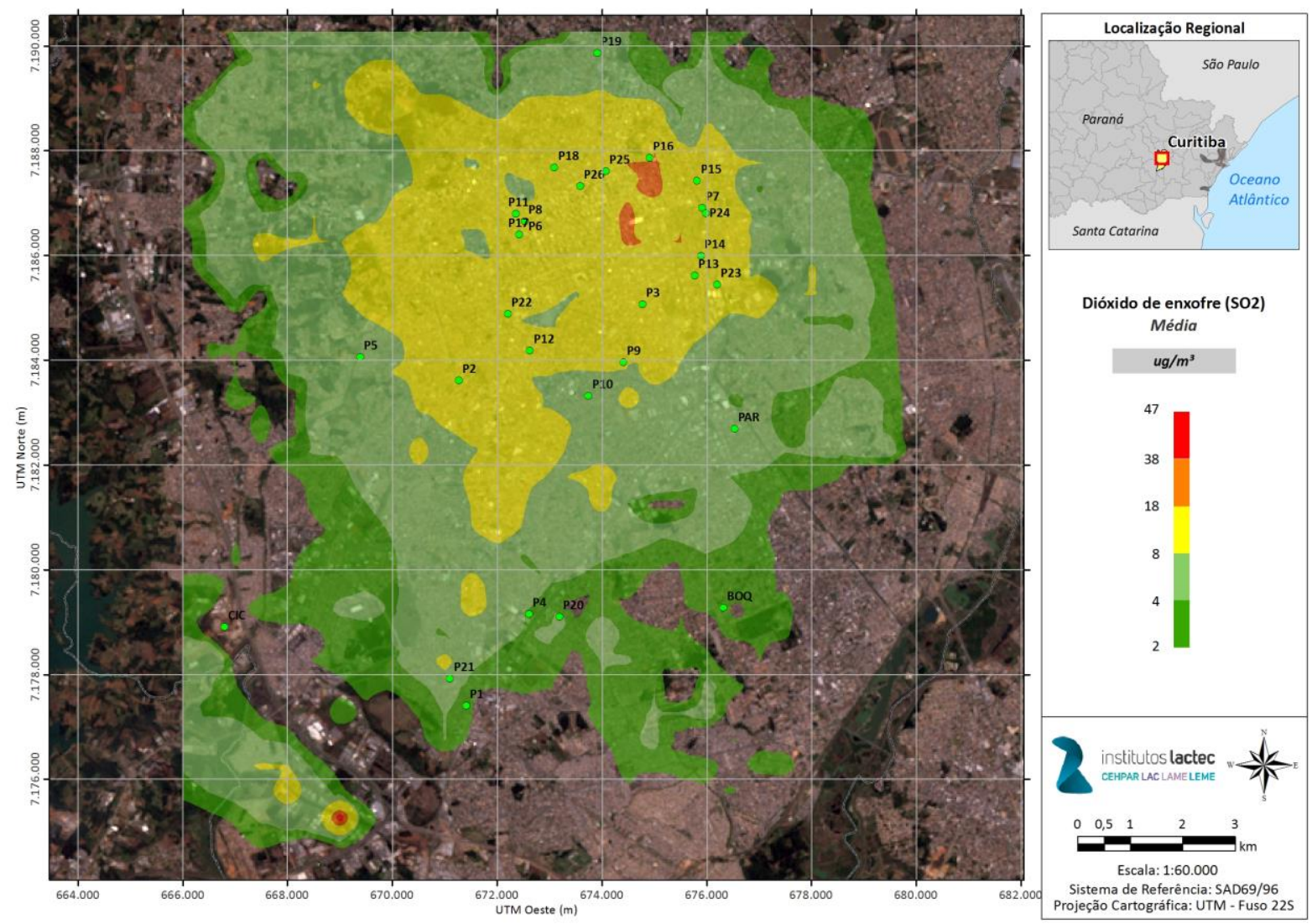

Figura 9 - Pluma da concentração média de SO2 obtido na modelagem Fonte: Os autores (2014).

As concentrações médias do dióxido de enxofre ficaram mais agrupadas na região do centro de Curitiba, ocorrendo uma mancha de concentração ao sul, devido a presença das indústrias (fontes fixas) em Araucária. As concentrações oscilaram entre $4,44 \mu \mathrm{g} / \mathrm{m} 3$ a $28,74 \mu \mathrm{g} / \mathrm{m} 3$.

\subsection{Hidrocarbonetos totais (THC)}

Apresenta-se na Figura 10 as concentrações de hidrocarbonetos totais (THC) para cada ponto do estudo. 


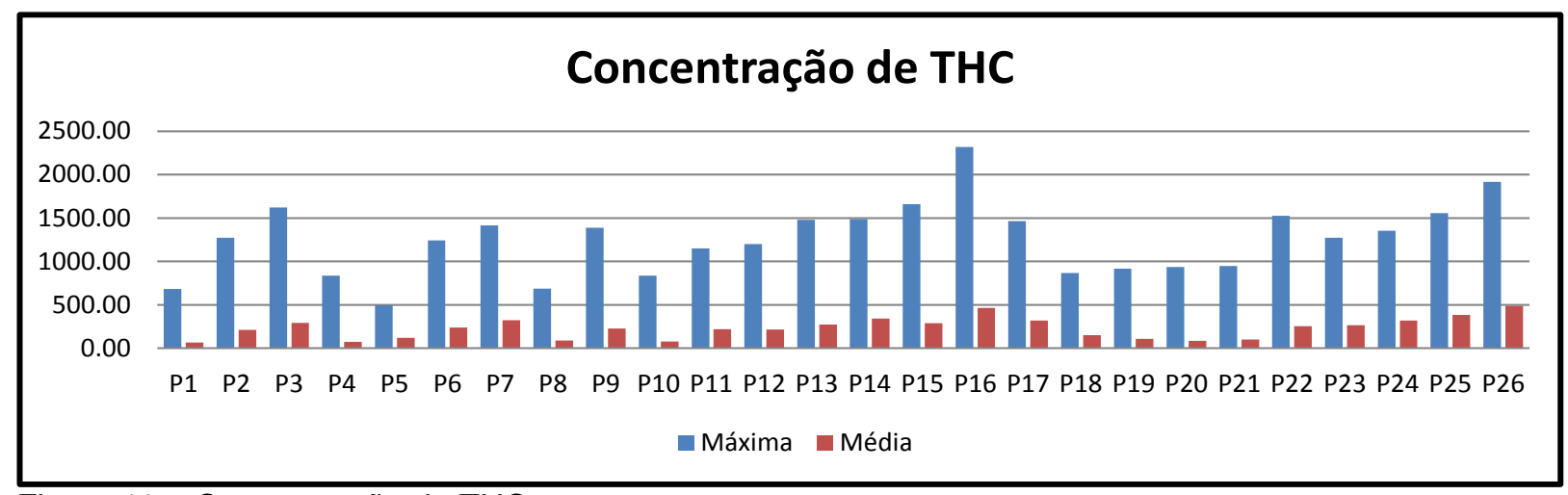

Figura 10 - Concentração de THC

Fonte: Os autores (2014).

As concentrações máximas de hidrocarbonetos totais não tiveram grande variância. A máxima verificada foi no P16 $(2317,17 \mu \mathrm{g} / \mathrm{m} 3)$ e os pontos P3, P15, P22, P25 e P26 ficaram com concentrações acima de 1527,00 $\mu \mathrm{g} / \mathrm{m} 3$.
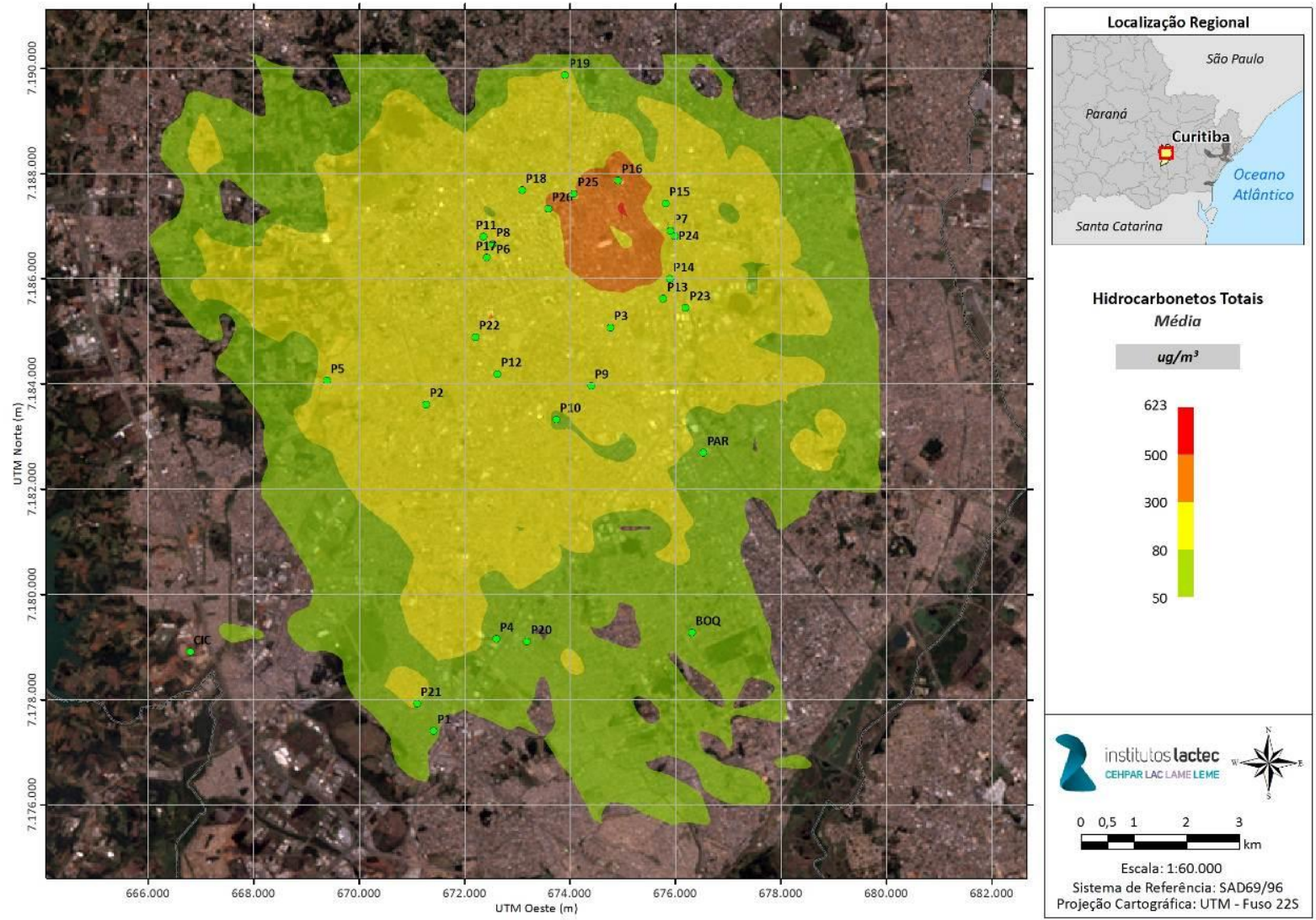

Figura 11 - Pluma da concentração média de Hidrocarbonetos Totais obtida na modelagem. Fonte: Os autores (2014).

A maioria das medias das concentrações modeladas nos pontos de estudo para os hidrocarbonetos totais ficaram entre $101,58 \mu \mathrm{g} / \mathrm{m}^{3}$ e $487,63 \mu \mathrm{g} / \mathrm{m}^{3}$ e. Ficando abaixo disto apenas os pontos P1, P4, P10 e P20. 
Dentre os níveis de concentrações analisados em cada um dos pontos de estudo, alguns tem destaque como sendo os detentores dos maiores índices de poluição na modelagem. O Ponto 16, está localizado na rua Constantino Marochi, esquina com a Avenida João Gualberto. Este local fica entre uma rua que possui uma canaleta exclusiva para a passagem de ônibus e a via rápida sentido bairro Cabral. Os poluentes relacionados a fontes móveis tiveram as maiores concentrações máximas obtidas na modelagem. O ponto 26 é o ponto que obteve as maiores médias dos 5 poluentes modelados e o ponto 1, situado na rua Francisco Raitani, obteve as menores médias dos poluentes modelados.

Analisando-se os gráficos dos escores e dos pesos resultantes dessa análise de componentes principais, foi possível identificar padrões de associação e similaridade tanto entre amostras quanto entre variáveis. Esses padrões serviram de base para estabelecer relações espaciais e/ou temporais entre os parâmetros de quantidade de bromélias, bem como as concentrações dos poluentes modelados. Segue a seguir a imagem da Componente Principal 1 obtida.

A imagem (Figura 12) é gerada como um produto do programa computacional (Python) e indica através de uma escala de cores e tamanho de círculos quais os níveis das correlações entre os pontos. Os pontos representam a localização das bromélias estudadas (P1 a P26). Quanto maior o círculo maior é a correlação. Quanto mais próximo a cor vermelha o círculo, representa maior correlação positiva e quanto mais próximo ao azul mais negativa. Os traços dentro das figuras representam as ruas que foram consideradas como fontes emissoras móveis (veiculares) modeladas dentro do programa AERMOD. O gráfico abaixo da figura representa os picos referentes as correlações positivas e negativas entre as classes das bromélias (B1, B2 e B3) e as classes das concentrações dos poluentes $(\mathrm{C} 1, \mathrm{H} 1$, M3, etc).

A CP1 indicou uma forte correlação negativa (Azul) para os pontos P1, P21, P4, P20, P8, P10, P5 e P19. As correlações mais positivas (Vermelho) estão entre os pontos P6 e o P13.

Segundo os picos de correlação verificados no gráfico abaixo da imagem as classes que tiveram correlação positiva foram B2, S3, N3, M4, H3 e C3 e correlações negativas $\mathrm{B} 1, \mathrm{~S} 1, \mathrm{~N} 1, \mathrm{M} 1, \mathrm{H} 1$ e $\mathrm{C} 1$. Como pode ser observado a classe com media infestação de bromélias (B2) se correlacionou positivamente com as classes referentes às concentrações intermediarias dos índices de poluentes modelados. $\mathrm{E} a$ classe com baixa concentração de bromélias se correlacionou negativamente com as classes mais baixas de concentração de poluentes.

Considerando que a imagem representa o mapa da cidade de Curitiba, os pontos 6 e 13 (correlação positiva) e sua relação com o uso do solo, podemos considerar que em ambos estão próximos a região central onde prevalecem poluentes de fontes móveis de emissão. Já nos pontos de correlação negativa, todos eles estão localizados na região periférica, onde o tráfego de veículos é menor e a concentração de poluentes atmosféricos também. 
Comp. principal 1, v.e. $31.57 \%$
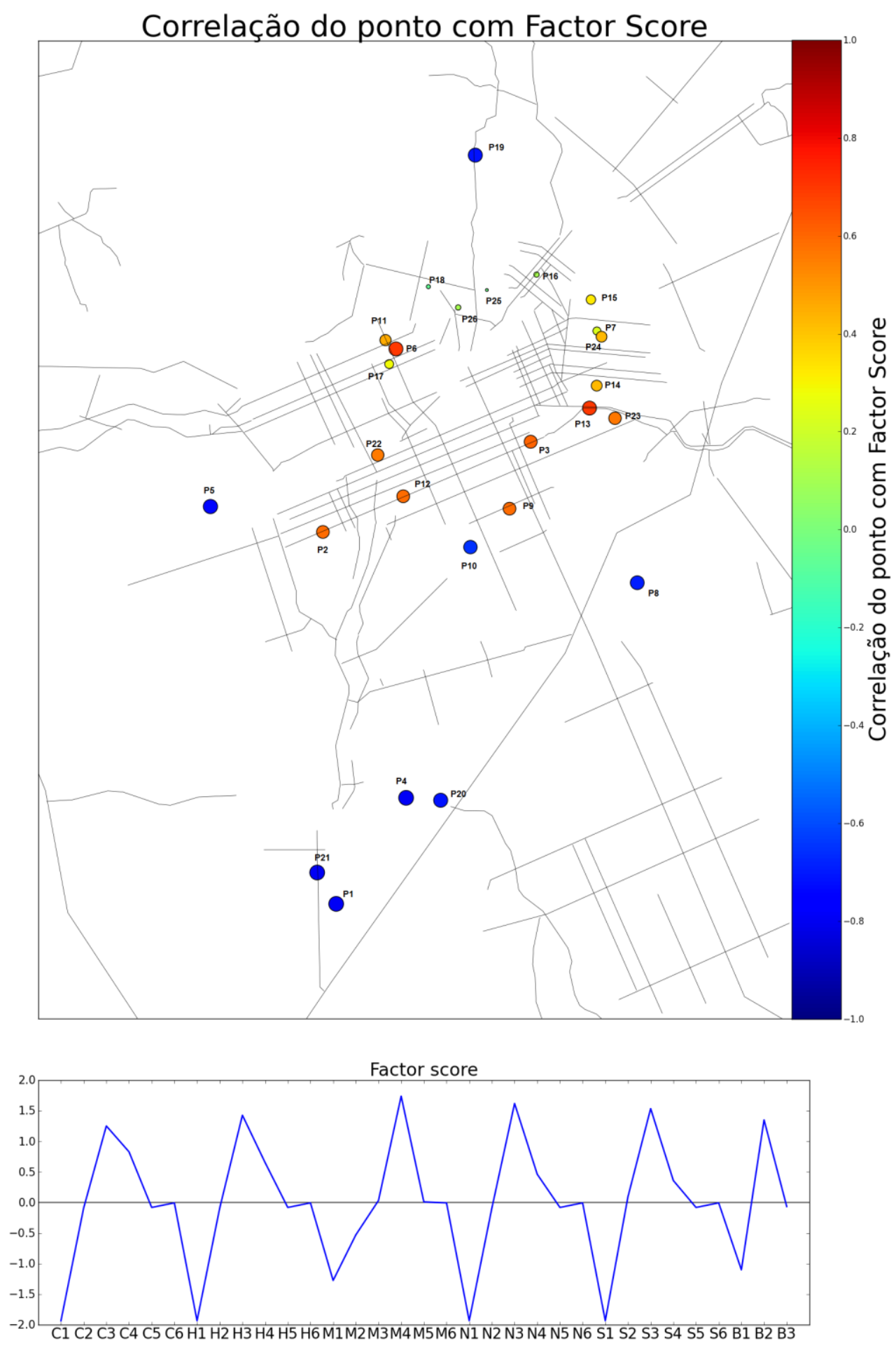

Figura 12 - Imagem da Componente Principal 1.

Fonte: Os autores (2014). 


\section{CONCLUSÃO}

O objetivo principal desta pesquisa foi verificar a existência de correlação a ocorrência de bromélias do gênero Tillandsia nos cabos de distribuição de energia elétrica com a emissão de poluentes atmosféricos e sua dispersão na atmosfera.

Grande parte dos pontos onde foi verificada a ocorrência de bromélias na rede elétrica fica em locais de intenso tráfego de veículos e a Analise de Componentes Principais realizada com os dados de campo e dados modelados indicou uma forte correlação entre os pontos da região central de Curitiba e os índices dos poluentes de origem móvel. Para pesquisas complementares indicasse a verificação qual dos componentes químicos das emissões veiculares que podem influenciar no crescimento vegetativo e populacional das bromélias que são encontradas nos cabos.

\section{REFERÊNCIAS}

[1] ZOTZ, GERHARD; WESTER, STEFAN. Growth and survival of Tillandsia flexuosa on electrical cables in Panama. Journal of Tropical Ecology. 26:123126. Cambridge University Press, 2009.

[2] ABRIL, A.B.; BUCHER, E.H. A comparison of nutrient sources of the epiphyte Tillandsia capillaries attached to trees and cables in Cordoba, Argentina. Journal of Arid Environments, v. 73, p. 393-395, 2009.

[3] PUENTE, M.E.; BASHAN, Y. The desert epiphyte Tillandsia recurvata harbous in nitrogen-fixing bacterium Pseudomonas stutzeri. Can. J. Bot., v. 72, p. 406-408, 1994.

[4] REITZ, R. Bromeliáceas e a Malária-bromélia endêmica. Flora llustrada Catarinense. Publ. Herbário Barbosa Rodrigues, Itajaí. 1983.

[5] BARRAT, J. Study reveals hazards of the high-wire life for bromeliads. Bromeliana, v. 49, n. 7, p. 1-4, 2012.

[6] KREMER, D. O gênero Tillandsia L. (Bromeliaceae - Tillandsioideae) no Estado do Paraná, Brasil. Ponta Grossa, 2011. 165 f. Dissertação (Mestrado em Biologia Evolutiva) -Universidade Estadual de Ponta Grossa e Universidade Estadual do Centro-Oeste.

[7] SUDGEN, A.M. Aspects of the ecology of vascular epiphytes in two Colombian cloud forests. II. Habitat preferences of Bromeliaceae in the Serrania de Macuira. Selbyana, v. 5, p. 264-273, 1981.

[8] BENZING, D.H. Vulnerabilities of tropical forests to climate change: the significance of resident epiphytes. Climatic Change, v. 39, p. 519-540, 1998.

[9] LUGO, A.E.; SCATENA, F.N. Epiphytes and climate change research in the Caribbean: a proposal. Selbyana, v. 13, p.123-130, 1992.

[10] WANNAZ, E. D.; CARRERAS, H. A.; RODRIGUEZ, J. H.; PIGNATA, M. L. 2012. Use of biomonitors for the identification of heavy metals emission sources. Ecological Indicators, 20, 163-169.

[11] RODRIGUEZ, J. H.; WELLER, S. B.; WANNAZ, E. D.; KLUMPP, A.; PIGNATA, M. L. 2011. Air quality biomonitoring in agricultural areas nearby to urban and industrial emission sources in Córdoba province, Argentina, employing the bioindicator Tillandsia capillaris. Ecological Indicators, 11, 1673-1680. 
[12] MARTÍNEZ-CARRILHO, M. A.; SOLÍS, C.; ANDRADE, E.; ISAAC-OLIVÉ, K.; ROCHA, M.; MURILLO, G.; BELTRÁN-HERNÁNDEZ, R. I.; LUCHOCONSTANTINO, C. A. 2010. PIXE analysis of Tillandsia usneoides for air pollution studies at na industrial zone in Central Mexico. Microchemical Journal, 96, 386390.

[13] GODOI, Ricardo H. M.GODOI, Ana F.L.; AZEVEDO, Roosevelt de; MARANHO, Leila T. Poluição e a densidade de vegetação: BTEX em algumas áreas públicas de Curitiba - PR, Brasil. Quim. Nova, Vol. 33, No. 4, 827-833, 2010.

[14] ENVIRONMENTAL PROTECTION AGENCY (EPA). AERMOD: description of model formulation. EPA-454/R-03-004. September 2004a.

[15] VASCONCELOS, Simone. Analise dos Componentes Principais (PCA). In http://www2.ic.uff.br/ aconci/PCA-ACP.pdf. Universidade Federal Fluminense. 2007. 